\title{
Complication occurs after odontectomy of mandibular third molar
}

\author{
Dicca Neldi Busra*, Tis Karasutisna*, Abel Tasman Yuza* \\ *Department of Oral and Maxillofacial Surgery Faculty of Dentistry Universitas Padjadjaran
}

ABSTRACT

Introduction: The average age for completely eruption of the mandibular third molar is age 20-25. The eruption of mandibular third molar sometimes prevented by several factors, caused this tooth becomes impacted. All impacted third molar should be removed with minor surgery, which called odontectomy. Several complications and complaint are accompanied with extraction of impacted third molar. The purpose of this study was to determine the prevalence rate of complications post-odontectomy of mandibular third molar, based on genders, age of the patients, the classification of impactions, and the day of postoperative control. Methods: The characteristics of this study was a descriptive survey that collected the secondary data from the medical records, which used the research papers to collect the data. Results: The results of this study show that there are 545 medical records of the patient included to the study, $62.7 \%$ complications occur in women. Complications often occur in age groups over 30 years (56.3\%). Conclusion: Most of complications occur in C position in class I, II, and III of Pell and Gregory classification. The most complications is oedem on the first day after surgery (43.1\%) and on the day of sutures opened (12.3\%).

Keywords: Complications, post-odontectomy, mandibular third molar.

\section{INTRODUCTION}

Maxillary and mandibular third molar will erupt completely at the age of 20 years old and on some people the eruption will continue until 25 years old. Teeth that are unerupted will be covered by soft tissue and a bit bone tissue if there was delayed eruption occurred. ${ }^{1}$

Impacted tooth is the teeth failed erupt into dental arch or the normal path or eruption was blocked by asjacent tooth, thick bone, dense soft tissue, and because of the surrounding pathological tissue. Impacted tooth can cause a variety of abnormalities that can interfere with the function of mastication. Abnormalities that can occur such as: periodontal abnormalities, pericoronitis infection, resorption of the root of the adjacent tooth, cyst formation, causing dental caries, pain, and can cause mandibular fracture. ${ }^{1,2}$ Impacted teeth will not erupt so as to prevent abnormalities performed a surgical procedure. ${ }^{1}$ The effort to remove the impacted mandibular third molars surgically is called odontectomy. ${ }^{2}$ Odontectomy is often accomponied by various complications and complaints. Complications that can occur include secondary bleeding, pain, edema, trismus, emphysema, dry sockets, hematoma, paresthesias, ecchymosis, loose sutures, and mandibular fractures. This complication can disrupt the normal mastication 
system and cause uncomfortable conditions in the oral cavity of sufferers. ${ }^{3}$

A study of impacted mandibular third molars was conducted in September and October 1986 at the UPF Teeth and Mouth Exodontia clinic at Hasan Sadikin Hospital in Bandung. The results showed there were $42 \%-52 \%$ of patients suffering from impacted mandibular third molars in which $44 \%$ $-59 \%$ of cases of impaction occurred in men and $40 \%-50 \%$ occurred in women. ${ }^{4}$ Other studies were also carried out in May and June 1999 in the Oral Surgery Section of Faculty of Dentistry Universitas Padjadjaran / Dr. RSUP Hasan Sadikin Bandung showed that there were $7.53 \%$ of the number of patients with impacted mandibular third molar odontectomy and of 66 patients there were $65 \%$ cases of complications on the first day and $19.6 \%$ on the fifth day. ${ }^{5}$

A similar study was also conducted in April to June 2005 at the Dental and Oral Hospital of the Faculty of Dentistry, Jember State University and found that the most common complication was edema and the most occurred in women was $47.62 \%$ while in men $20.63 \% .^{2}$

An oral and maxillofacial surgeon at the oral surgery department of the Faculty of Dentistry at Laval University in Quebec, Canada, Drg. Blondeau, conducted a study of complications after odontectomy of the mandibular third molar during January to December 2003. The results showed that out of 550 patients who received odontectomy, 327 patients between 12 to 55 years old experienced complications after an odontectomy (6.9\%). Complications are common in women (10.2\%) with an age range of 24-29 years old. Based on the classification of impactions of Pell and Gregory's mandibular third molars, complications occur in the classification of IIC (12\%) and IIIB (19\%).

Based on the complications caused by odontectomy, the authors are interested in conducting research on the description of complications cases that occur after the odontectomy action of the mandibular third molar in the Oral and Maxillofacial Surgery Department of Faculty of Dentistry Universitas Padjadjaran/ RSUP Dr. Hasan Sadikin Bandung period 2008 to 2010 and later this research is expected to be a reference and information material for dentistry students and health professionals, especially dentists.
The purpose of this research is to find out the prevalence of complications that occur after odontectomy in mandibular third molars, based on sex, age, classification of impacted mandibular third molars.

\section{METHODS}

The type of research is descriptive survey research with the type of morbidity survey, which is to find out and get a picture of the magnitude of complications that often occur after an odontectomy in the mandibular third molar in the Oral and Maxillofacial Surgery Department of Faculty of Dentistry Universitas Padjadjaran / RSUP Dr. Hasan Sadikin Bandung which will be compared based on sex, age, classification of impacted mandibular third molars, and postoperative visit day.

The study was conducted by taking secondary data from a patient's medical record report in the Oral and Maxillofacial Surgery Section of Faculty of Dentistry Universitas Padjadjaran / Dr. RSUP Hasan Sadikin Bandung within a period of three years starting in January 2008 until December 2010. The study population was all patients who came to the Oral and Maxillofacial Surgery Faculty of Dentistry Universitas Padjadjaran / RSUP Dr. Hasan Sadikin Bandung to obtain odontectomy for mandibular third molar from the period January 2008 to December 2010. The sampling technique was purposive sampling. The sample in this study were all patients who experienced complications after receiving a mandibular third molar odontectomy with the criteria that there is complete data in the patient's medical record regarding the patient's sex, patient's age, the welding of the impacted third molar, and the patient's postoperative visit on the first day and the day of suture opening.

\section{RESULTS}

Patients who received the procedure of mandibular third molar odontectomy in the Oral and Maxillofacial Surgery Faculty of Dentistry Universitas Padjadjaran / RSUP Dr. Hasan Sadikin Bandung within a period of three years from January 2008 to December 2010 recorded in a patient visit book totaling 1843 patients. The files 
stored in the Outpatient Medical Records Section for data collection were 727 patients, of which 545 patients $(75 \%)$ met the study requirements. The number of samples studied were 545 people consisting of 245 men and 300 women.

Based on the gender, patients who received a mandibular third molar odontectomy consisted of 245 male patients and 300 female patients. Of the 245 male patients, there were 107 patients (43.7\%) who experienced complications after the mandibular third molar odontectomy. Out of the 300 female patients, 188 patients $(62.7 \%)$ had complications after odontectomy of the mandibular third molar. Complete results can be seen at table 4.1 and diagram 2.

Patients who received odontectomy for lower third molars were divided into four groups based on age, namely the age group of less than 20 years totaling 36 patients, the age group of 20-25 years totaling 179 patients, the age group of 26-30 years totaling 124 patients, and the age group of more than 30 years was 206 patients.

There were 20 patients $(55.6 \%)$ who had complications after odontectomy of the mandibular third molar in the age group of less than 20 years. In the age group of 20-25 years, there were 90 patients $(50.3 \%)$ who had complications after the odontectomy of the mandibular third molar. In the 26-30 age group there were 69 patients (55.6\%) who experienced complications after odontectomy of the mandibular third molar. There are 116 patients (56.3\%) who have complications over the age group after receiving a mandibular third molar odontectomy. Details of the data can be selected in table 2 and diagram 3.

The complications after odontectomy of the mandibular third molar consisted of nine groups based on the Pell and Gregory impaction classification. Class I position A, there were 129 patients in which 54 patients $(41.9 \%)$ experienced complications after receiving a mandibular third molar odontectomy. Class I position B there were 45 patients in which 25 patients (55.6\%) had complications after receiving a mandibular third molar odontectomy. Class I position C has only 1 patient $(100 \%)$ and has complications after the odontectomy of the lower third molar.

Class II position A, there were 223 patients of which 123 patients (55.2\%) had complications. Class II position B there are 108 patients of which

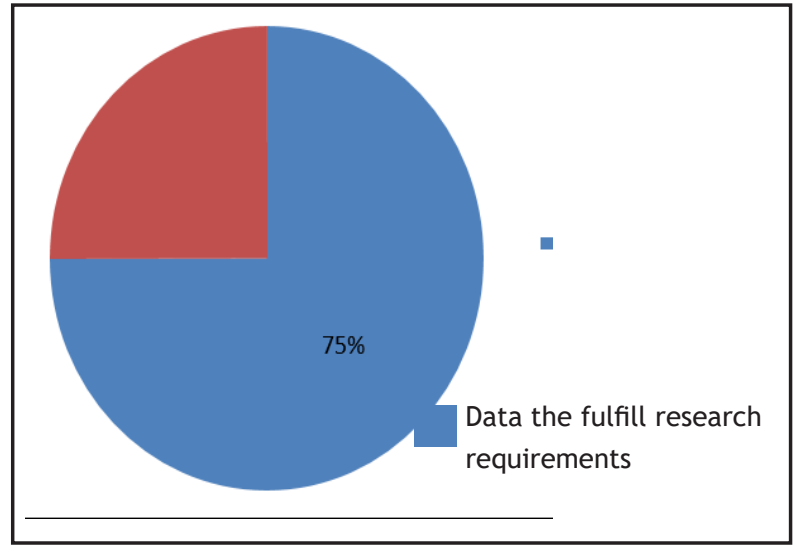

Diagram 1. Amount of Data of Mandibular Third Molar Odontectomy Patients in 2008-2010 that Fulfilled Research Requirements

Table 1 . Distribution of Complications after Odontectomy of Mandibular Third Molar Based on Gender

\begin{tabular}{lcclcc}
\hline Gender & N & K & $\begin{array}{c}\text { Percentage } \\
\text { (\%) }\end{array}$ & NK & $\begin{array}{c}\text { Percentage } \\
\text { (\%) }\end{array}$ \\
\hline Male & 245 & 107 & 43.7 & 138 & 56.3 \\
Female & 300 & 188 & 62.7 & 112 & 37.3 \\
\hline
\end{tabular}

Note: $\mathrm{N}=$ Number of patients; $\mathrm{K}=$ Complications based on sex; NK= Non complications based on sex.

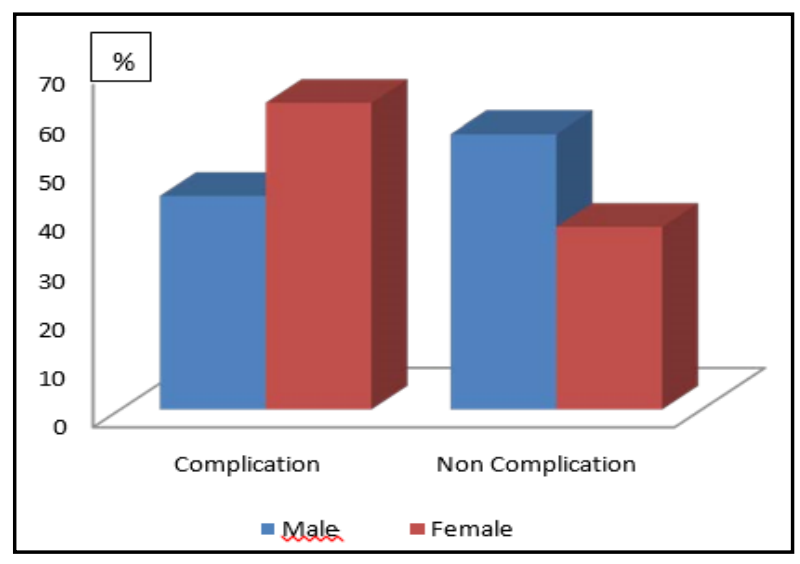

Diagram 2 . Distribution of complications after the mandibular third molar odontectomy Based on Gender

Table 2. Distribution of Complications Post Odontectomy of Mandibular Third Molar by Age Group

\begin{tabular}{cccccc}
\hline Age Group & N & K & $\begin{array}{c}\text { Percentage } \\
\text { (\%) }\end{array}$ & NK & $\begin{array}{c}\text { Percentage } \\
\text { (\%) }\end{array}$ \\
\hline <20 years old & 36 & 20 & 55.6 & 16 & 44.4 \\
20-25 years & 179 & 90 & 50.3 & 89 & 49.7 \\
26-30 years old & 124 & 69 & 55.6 & 55 & 44.4 \\
$>$ 30 years old & 206 & 116 & 56.3 & 90 & 43.7 \\
\hline
\end{tabular}

Note: $\mathrm{N}=$ Number of Patients; $\mathrm{K}=$ Complications based on age group; NK = Non-complications based on age group 
63 patients (58.3\%) have complications. Class II position $C$, there were 18 patients in which 12 patients $(66.7 \%)$ who experienced complications after odontectomy of the lower third molar teeth.

Class III position $\mathrm{A}$, there were 4 patients in which 3 patients $(75 \%)$ had complications af-

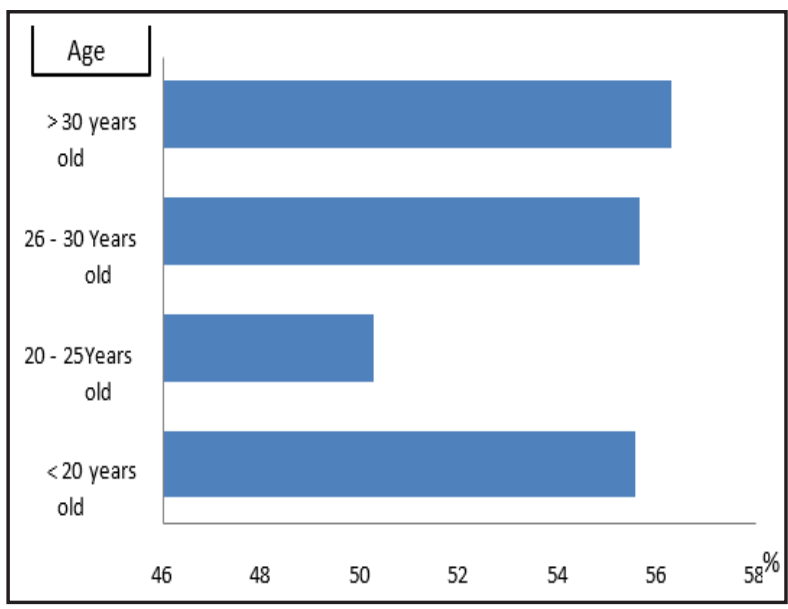

Diagram 3. Distribution of Complications after Odontectomy for Lower Molar Tooth by Age Group ter odontectomy of the lower third molar. Class III position $B$ there are 12 patients where 9 patients (75\%) have complications. Class III position C, there are 5 patients in which all (100\%) experience complications after receiving a mandibular third molar odontectomy. Can be explained in table 3 .

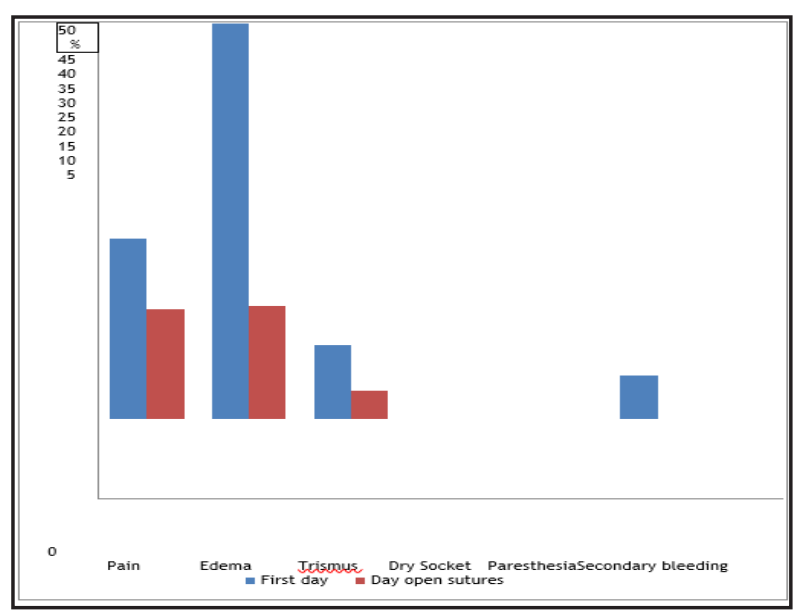

Diagram 4. Distribution of complications after odontectomy of lower molar teeth based on post operative visit days

Table 3. Distribution of Complications after Odontectomy Action of Lower Molar Third Tooth Based on Pell and Gregory Classification

\begin{tabular}{ccccccc}
\hline Pell and Classification Gregory & N & K & Percentage (\%) & NK & Percentage (\%) \\
\hline \multirow{2}{*}{ Class I } & A & 129 & 54 & 41.9 & 75 & 58.1 \\
& B & 45 & 25 & 55.6 & 20 & 44.4 \\
\multirow{3}{*}{ Class II } & C & 1 & 1 & 100 & 0 & 0 \\
& A & 223 & 123 & 55.2 & 100 & 44.8 \\
& B & 108 & 63 & 58.3 & 45 & 41.7 \\
Class III & C & 18 & 12 & 66.7 & 6 & 33.3 \\
& A & 4 & 3 & 75 & 1 & 25 \\
& B & 12 & 9 & 75 & 3 & 25 \\
\hline
\end{tabular}

Note: $\mathrm{N}=$ Number of Patients per classification; K= Complications based on classification; NK= Non-complications based on classification

Table 4. Distribution of Complications after an Act of a mandibular third molar odontectomy by postoperative visit day

\begin{tabular}{ccccccc}
\hline \multirow{2}{*}{ No } & \multirow{2}{*}{ Kinds of Complications } & N & \multicolumn{2}{c}{ Complications of Day I } & \multicolumn{2}{c}{ Complications of Day V / VII (open Stitches) } \\
\cline { 4 - 7 } & & amount & Percpercentage (\%) & amount & Percpercentage (\%) \\
\hline 1 & Pain / Pain & 545 & 107 & 19.6 & 65 & 11.9 \\
2 & Edema & 545 & 235 & 43.1 & 67 & 12.3 \\
3 & Trismus & 545 & 44 & 8.1 & 17 & 3.1 \\
4 & Dry Socket & 545 & 0 & 0 & 1 & 0.2 \\
5 & Paresthesias & 545 & 1 & 0.2 & 4 & 0.7 \\
6 & Secondary Bleeding & 545 & 26 & 4.8 & 3 & 0.6 \\
7 & Emphysema & 545 & 0 & 0 & 0 & 0 \\
8 & Stitching off & 545 & 0 & 0 & 0 & 0 \\
9 & Mandibular fracture & 545 & 0 & 0 & 0 &
\end{tabular}


Out of the 545 patients who received the mandibular third molar odontectomy studied, there were 107 patients (19.6\%) who experienced pain on the first day and 65 patients $(11.9 \%)$ on the day the stitches were opened. Edema occurred in 235 patients $(43.1 \%)$ on the first day and 67 patients $(12.3 \%)$ on the day the suture was opened. Trismus occurred in 44 patients on the first day $(8.1 \%)$ and 17 patients (3.1\%) on the day the suture was opened. Secondary bleeding occurred in 26 patients $(4.8 \%)$ on the first day and 3 patients $(0.6 \%)$ on the day of the suture opening. Paresthesias occurred in 1 patient $(0.2 \%)$ on the first day and 4 patients $(0.7 \%)$ on the day of the suture opening. Percentage of complications after odontectomy of the lower third molar based on the day of postoperative visit can be seen in table 4 and diagram 4.

\section{DISCUSSION}

Diagram 1 shows the number of patients who received odontectomy in the mandibular third molar in the Oral and Maxillofacial Surgery Faculty of Dentistry / RSUP Dr. Hasan Sadikin Bandung within a period of three years from January 2008 to December 2010 and who met the study requirements were 545 patients out of 727 patients whose medical record files were still stored in the Outpatient Medical Record Section of Dr. RSUP Hospital Hasan Sadikin Bandung, about $75 \%$ of all available medical records.

Table 1 and Diagram 2 show the percentage of complications after odontectomy of the mandibular third molar by sex. Female patients who experienced complications after receiving a mandibular third molar odontectomy were 188 people $(62.7 \%)$ of the 300 patients who received a mandibular third molar odontectomy. Male patients who experienced complications after receiving a mandibular third molar odontectomy were 107 people $(43.7 \%)$ out of 245 patients who received a mandibular third molar odontectomy.

The results showed that complications after odontectomy of mandibular third molars occurred in many women. Previous studies have shown that complications are more common in women (63.5\%) compared to men (36.5\%). ${ }^{2}$

Another study conducted in Canada also showed that complications after odontectomy of lower third molars were more common in women (58.4\%) compared to men (41.6\%). ${ }^{6}$ This is probably due to differences in psychic conditions between men and women. Women may feel more anxious and anxious when receiving surgery than men. The comfort and tranquility of patients in the face of surgery provide the flexibility of dentists to work more effectively and efficiently to minimize complications after surgery. ${ }^{1}$

Tables 2 and Diagram 3 shows the percentage of complications after odontectomy action mandibular third molar teeth by age group. Patients in the age group of less than 20 years who experienced complications after the odontectomy of the mandibular third molar teeth totaled 20 people $(55.6 \%)$ of the 36 patients who received the mandibular third molar odontectomy with an age group of less than 20 years. Patients in the age group of 20-25 years who experienced complications after the odontectomy of the lower third molar teeth totaled 90 people $(50.3 \%)$ out of 179 patients in the 20-25 year age group who received odontectomy of the mandibular third molar.

Patients in the 26-30 years age group who experienced complications after the odontectomy of the mandibular third molar teeth totaled 69 people $(55.6 \%)$ out of 124 patients in the 26-30 year age group who received odontectomy for the mandibular third molar. Patients in the age group of more than 30 years who experienced complications after the odontectomy of the lower third molar teeth amounted to 116 people (56.3\%) of 206 patients in the 20-25 year age group who received odontectomy of the mandibular third molar.

The results showed that complications after odontectomy of the mandibular third molar were more common in the age group of more than 30 years. Older patients are less able to tolerate surgical procedures and cure longer than younger patients. Periodontal tissue healing is slower due to poor and incomplete regeneration in the periodontal tissue of older patients. ${ }^{1}$ Calcification of bone will also increase and the accompanying pathological conditions will also be more in line with age so that it requires removal of more bones that affect the process of wound healing after surgery. ${ }^{7}$

Table 3 shows the percentage of complications that occurred after the odontectomy of the lower third molar according 
to the Pell and Gregory classification. There were 129 class I class I patients with 54 patients (41.9\%) having complications after receiving a mandibular third molar odontectomy. Class I position B there were 45 patients in which 25 patients $(55.6 \%$ ) had complications after receiving a mandibular third molar odontectomy. Class I position $\mathrm{C}$ has only 1 patient $(100 \%)$ and has complications after the odontectomy of the lower third molar.

There are 223 patients with Class II position A, of which 123 patients (55.2\%) have complications. Class II position B there are 108 patients of which 63 patients (58.3\%) have complications. Class II position $C$, there were 18 patients in which 12 patients $(66.7 \%)$ who experienced complications after odontectomy of the lower third molar teeth.

Patients with class III position A there were 4 patients in which 3 patients $(75 \%)$ had complications after odontectomy of the lower third molar. Class III position B there are 12 patients where 9 patients $(75 \%)$ have complications. Class III position $C$, there are 5 patients in which all $(100 \%)$ experience complications after receiving a mandibular third molar odontectomy. ${ }^{1}$

The results showed that complications that occur after the odontectomy of lower third molars often occur in class I position C, class II position C, and position III C. Position C according to Pell and Gregory classification is where the highest peak of the lower third molar is located below lower second molar cervical line, in other words the lower third molar teeth buried in bone. Odontectomy performed in this position will be more difficult and requires a lot of removal of soft tissue and bone. The difficulty of the surgery process causes the surrounding tissue to be at high risk of trauma from the surgical instruments used. This affects the healing process after surgery. The conclusion was that the higher the level of difficulty in accordance with the impacted tooth classification, the greater the possibility of postsurgical complications.

Table 4 and Diagram 4 show the percentage of types of complications that occur after odontectomy of the lower third molar based on the day of the postoperative visit. Out of the 545 patients who received the mandibular third molar odontectomy studied, there were 107 patients (19.6\%) who experienced pain on the first day and
65 patients $(11.9 \%)$ on the day the stitches were opened. Edema occurred in 235 patients $(43.1 \%)$ on the first day and 67 patients $(12.3 \%)$ on the day the suture was opened. Trismus occurred in 44 patients on the first day $(8.1 \%)$ and 17 patients $(3.1 \%)$ on the day the suture was opened. Secondary bleeding occurred in 26 patients $(4.8 \%)$ on the first day and 3 patients $(0.6 \%)$ on the day of the suture opening. Paresthesias occurred in 1 patient $(0.2 \%)$ on the first day and 4 patients $(0.7 \%)$ on the day of the suture opening.

The results showed that edema was a frequent complication after the odontectomy of the lower third molar on the day of the first postoperative visit and at the opening of the suture. The second most common complication is pain. Edema occurs as a result of local trauma that occurs as a sign of an inflammatory process accompanied by redness and pain. Edema can involve tissue in the oral cavity and involve the muscles of the cheeks and surrounding areas resulting in swelling of the cheeks. Edema is a normal tissue reaction from injury at each tooth extraction and surgery. The complications that occur after the odontectomy of the lower third molar are also caused by the patient's own actions. ${ }^{2}$ Complications can occur if the patient does not follow the post-surgical instructions given by the dentist. Actions that can lead to surgical complications include, for example, patients not taking drugs given after surgery, patients playing scars with their hands or tongue, patients suctioning after surgery, and bad habits of patients who do not maintain oral hygiene. ${ }^{1}$

\section{CONCLUSION}

Complications after odontectomy of mandibular third molars which were found to be more common in females compared to males, in the age group who had more frequent complications after molar odontectomy the lower jaw is the age group of more than 30 years, complications after odontectomy of the mandibular third molars were found to be more common in position $\mathrm{C}$ based on Pell and Gregory classification , and complications after the odontectomy of the lower third molar is edema, both during the first day of control and when the stitches are opened. 


\section{REFERENCES}

1. Peterson LJ, Edward Ellis, James R Hupp, Myron R. Contemporary Oral and Maxillofacial Surgery. $4^{\text {th }}$ ed. St. Louis: Mosby. Halaman: 2003. p. 185-237.

2. Dwipayanti A, Adriatmoko W, Rochim A. Komplikasi Post Odontektomi Gigi Molar Ketiga Rahang Bawah Impaksi. J PDGI 2009:58(2): 20-24.

3. Pederson WG. Buku Ajar Praktis Bedah Mulut. Jakarta: EGC. 1996. p. 83-100.

4. Budiasih SR. Prevalensi Gigi Molar Tiga Impaksi pada Penderita yang Berkunjung ke Unit
Pelaksana Fungsional Gigi dan Mulut Rumah Sakit DR. Hasan Sadikin Bandung. Skripsi. FKG UNPAD. 1987. p. 41-47.

5. Desianti. Insidensi Komplikasi Pascaodontektomi Molar Tiga Bawah Impaksi. Skripsi. FKG UNPAD. 1999. p. 37-50.

6. Blondeau F, Daniel NG. Extraction of Impacted Mandibular Third Molar: Post Operative Complications and Their Risk Factors. J Can Dent Assoc. 2007 May;73(4):325.

7. Koerner KR. Manual of Minor Oral Surgery for the General Dentist. Berlin: Blackwell Munksgaard. 2006. p. 49-71. 